\title{
Review: Effects of Using Different Materials on Filtration Process
}

\section{of Wastewater}

\author{
Ahmed S. Al Chalabi' ${ }^{1}$ Rafi M. Qasim ${ }^{2}$, Abdulameer Q. Hasan ${ }^{3}$ \\ Ass. Lecture ${ }^{1}$, Lecture ${ }^{2,3}$ \\ Department of Environmental and Pollution Eng. 1,3 \\ Department of Fuel and Energy Eng. ${ }^{2}$ \\ Basra Engineering Technical College \\ Southern Technical University \\ Al Basra, Iraq
}

\begin{abstract}
In many low-income countries, access to improved sanitation is frequently lacking and nearly 90 percent of sewage is discharged without treatment into water bodies. Even with the immense social and technical developments, many researchers around the world still concentrate on pollution issues. Filter unit which consist of single media or mixed media can be improve by using different material with various physical and chemical properties, so, this property must have positive influence when mixed with original material of filter or in the other word the new material must promote, also alter the hydraulic and environment behavior of filter unit and this will reflect on treatment coast of wastewater and drinking water regardless the source. The inequality in physical and chemical properties of mixed or added material must increase the operation efficiency by reduce the virus and pathogenic, also increase the removal of suspended solid, diminish the water salinity and reduce the concentration of harmful materials. Over all the modified filter unit must work with satisfactory level as compared with standard filter unit considering the operation and maintenance coast. In general, the modification in filter unit lead to the dramatic increase in removal of total suspended solid with increase in $\mathrm{COD}$ and $\mathrm{BOD}_{5}$ level, also increase the removal of chemical material.
\end{abstract}

Key Words: Water Treatment, Wastewater Treatment, Filtration, Sand Filter.

\section{INTRODUCTION}

Filtration process of drinking water and wastewater has a vital role in human life and housing standard from the past to the present period. It is very important to assess the quality of material which is used in this system in order to improve the efficiency of the removal suspended material. Several researchers struggle deal with this issue from the past till the day in order to arrive at the effective solution to the problem of water clarity in the filtration method by adopting additional material mix ed with sand.

The solid waste produced by the combustion of coal due to the chemical and physical characteristics of this material is defined by ash flying and coal bed ash, so that it can be used in waste water treatment. The radiological evaluation of the wastewater treatment plant based on the use of coal ash as filters was analyzed in this study. In the installation of the wastewater treatment plant, three treatment measures are used: coal fly ash filtration, coal bed ash filtration, and sand filtration. The findings obtained suggest that coal ash is a safe substance and does not pose much risk of radiation, making it an effective wastewater treatment substance [1].

This work investigated the biological filter (which consist of dune sand) treatment efficiency under the impact of the salinity wastewater. This work involved developing six identical filtration columns with the same sand from the same region where wastewater is fed to the filters at six different salinity concentrations corresponding to electrical conductivity. The performance of the filtration process has been evaluated by calculating changes in the overall $\mathrm{pH}$ of the treated water, including the chemical 
demand for oxygen and conductivity. The study results showed that the change in the salinity of waste water had a negative impact on organic matter degradation [2].

This study investigated the impact of high organic material which included in the wastewater during the oil production. The results obtained showed that both pre-treatments were able to reduce the overall suspended solid by 73 percent and raise the $\mathrm{pH}$ by 6 percent. The three stage filtration method anaerobic filtration prototype has the potential to minimize the BOD, COD and TSS levels of waste water [3].

The feasibility of coarse / fine sand filtration for extracting organic materials from turkey wastewater processing was explored in this study. Sand filtration was tested with three organic and hydraulic loading operations. Three groups of bio-sand reactors have been built, and there are two reactors in each group. Each reactor includes, at the bottom, a layer of pea gravel $5 \mathrm{~cm}$ thick, then 46 $\mathrm{cm}$ of fine sand, and then $15 \mathrm{~cm}$ of coarse sand. For each sand bioreactor, they were applied at different hydraulic load rates for two days. Repeating shafts with the same hydraulic load were made up of each party. Achieved optimum care quality. TOC and $\mathrm{BOD}_{5}$ removal were $>94$ percent during 80 days of column operation at low and medium hydraulic loading speeds. The removal rate decreased at the maximum hydraulic loading rate and even the depletion decreased at the maximum hydraulic loading rate, after making a black zone in the upper layer of fine sand on day 30 for one reactor and day 50 for the other. Sand filtration is a feasible treatment for turkey wastewater treatment in this study, and the efficiency and lifetime of the process are linked to the range of hydraulic loading [4].

Many industrial sectors, including the agro-food, petroleum and leather industries, are likely to produce highly saline waste water. The release of such waste water containing both a high salinity and a high organic content without prior treatment is considered to adversely affect aquatic life, water potability and agriculture. Therefore, regulation is becoming stricter and the treatment of salty waste water is now obligatory in many countries, both for organic matter and salt removal. Saline effluents are conventionally treated by physico-chemical means, as salts (mainly $\mathrm{NaCl}$ ) strongly inhibit biological treatment. However, as the cost of physicochemical therapy is particularly high, alternative systems for the treatment of organic matter are increasingly being studied. Anaerobic or aerobic biological therapy is involved in most such processes. While biological treatment of carbonate, nitrogen \& phosphorus contamination has been shown to be probable at high salt concentrations, output is dependent on proper biomass adaptation or the use of halophilic species. The turbidity issues inherent in saline effluents are another important restriction [5].

This study evaluated the use of a novel sand filtration method that, by using a periodic dilute acid rinse to preserve its sorptive capacity, exploits the natural capacity of filter sand to sorb radium. To evaluate distribution coefficients, batch studies were performed so that performance estimates could be made. It was possible to conduct laboratory pilot studies using a partially weakened performance estimate. Laboratory pilot experiments using partially softened iron floes during daily rinsing using $\mathrm{pH} 1$ $(0.36 \%)$ or $\mathrm{pH} 29-11 \mathrm{pCi}^{226} \mathrm{Ra} / \mathrm{L}$ collected from existing sand filters in a city whose supply is treated for iron removal. When simultaneous iron and radium removal was attempted, removals in the field were lower. Furthermore, estimates of the total sand sorptive potential obtained in the batch performance [6].

Irrigation of vegetables by using polluted wastewater stream is a common problem in many developing countries, and causes microbial contamination of vegetables and this occurs owing to the available source of nutrients and water is the wastewater, and the treatment of the wastewater treatment is often inadequate. The feasible option which is used to avoid the microbial contamination risk by adopt a multi-barrier approach on-farm treatment. Based on evidence a biochar (non-activated charcoal) filters give a reasonable microbe removal from the wastewater which depend on the designed hydraulic loading rate of the sand filters, even though their suitability under on-farm conditions has not been checked. This study analyzed the combined impact of several variables on the microbial removal of diluted waste water through on-farm biochar filtration, taking into account the correlations between removal efficiency and hydraulic load rate [7].

This study investigated the performance in terms of organic matter, total nitrogen (Tot-N), Escherichia coli and salmonella removal using a filter containing biochar as a medium, and the effects of hydraulic loading rate (HLR) on pollutant removal. Where the vertical and horizontal flow system was used, which works as follows: (i) an aerobic vertical flow filter (VF) that percolates waste water through the biochar medium in unsaturated mode; and (ii) a horizontal flow filter (HF) that percolates waste water through the biochar medium in unsaturated mode; and a horizontal flow filter (HF) that saturates the biochar with water and restricts access to air, enabling anaerobic conditions and improving denitrification (Fig .1). The performance of the vertical and horizontal flow system was found to be high with regard to the long-term removal of organic matter, nitrogen and other contaminants, bacteria and viruses, as well as the absence of blockages, suggesting good robustness of the combined VF-HF biochar filter system [8]. 


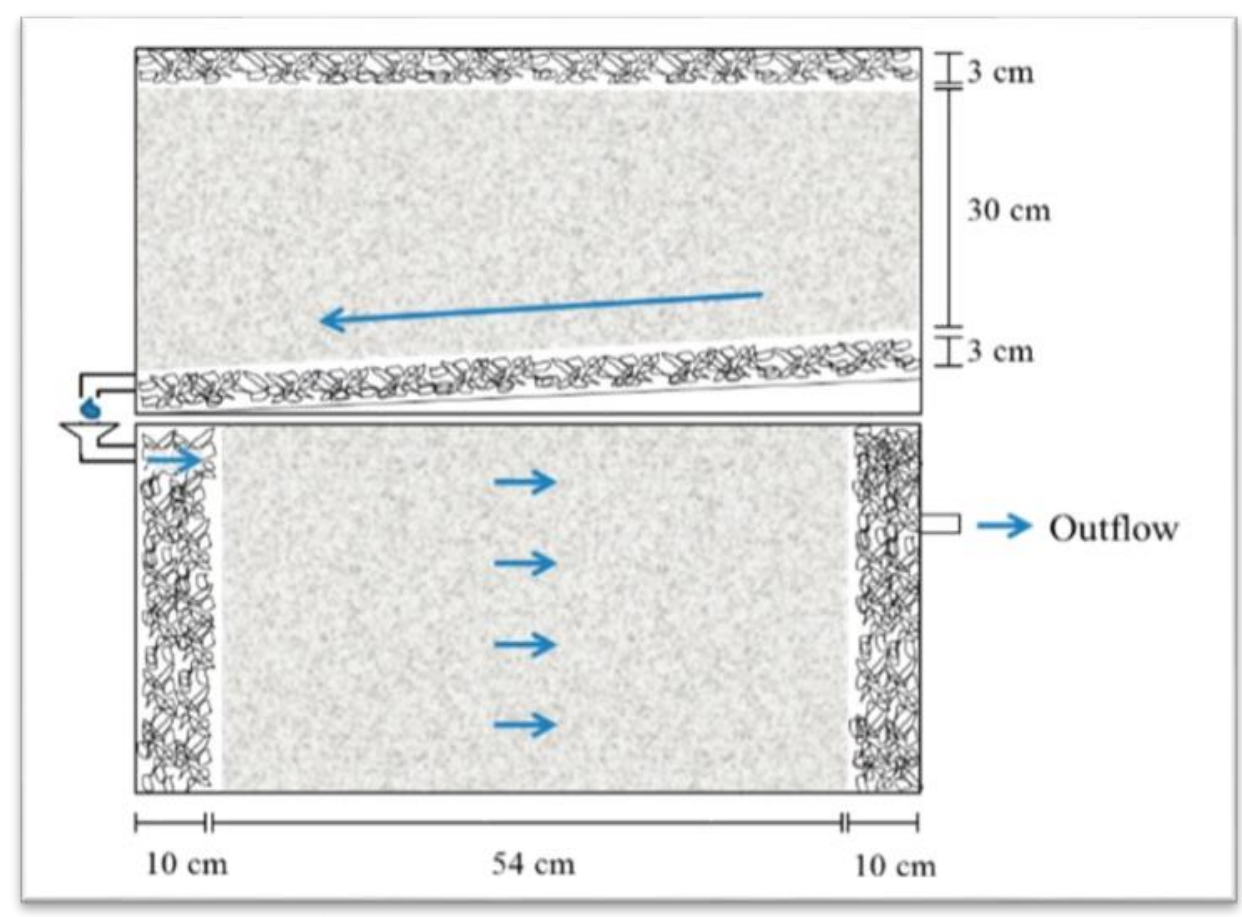

Fig. 1: Combined VF-HF system [8]

The goal of this study was to develop and evaluate an efficient system of treatment of waste water in poor countries. For anaerobic filtration of waste water, biochar and wood chips, which are both locally available and inexpensive materials, were used and their suitability was assessed as a standard reference material compared to gravel. The filters were supplied with untreated waste water from the sewage treatment plant with a low hydraulic loading rate. Anaerobic filters have been found to minimize water pollutions and enhance water quality, making them highly effective in the treatment of waste water in poor countries. Biochar filters have been found to minimize COD, TOC, turbidity, and eliminate much more bacteria and viruses than wood chip and gravel filters, showing the superior properties of biochar for the treatment of waste water [9].

The growing urbanization, the growing population and the growing need for agricultural water put great pressure on the availability of fresh water. High costs and inadequate central sewage treatment plants, especially in low-income countries, have made it necessary to identify new fresh water sources. Wastewater reuse can constitute an alternative source of water. Except for toilet water, greywater is all household waste water which makes up 80 percent of household waste water. Gray water can be reused for irrigation instead of waste in agricultural areas, thus reducing the burden on fresh water supplies and thereby protecting the environment and reducing water costs. Because of its source, gray water contains bacteria and viruses as well as some chemicals, so the reuse of raw gray water has a damaging effect on the soil and can pollute groundwater, surface water and lead to the spread of disease. Therefore, the aim of this research is to pass gray water on filters that contain local and inexpensive filter materials to get rid of bacteria and viruses, and the resulting water is used for irrigation. As filter media, bark, biochar, and activated charcoal have been used in column filters. These materials were tested by calculating, before and after filtration, the agglomeration of certain chemical properties and the turbidity of bacteria and viruses. The activated charcoal filter is found to be more effective at reducing some of the chemical parameters. Bark filters have an acidic effect on the graywater being filtered and have been shown to be less effective in reducing the analyzed viruses. Biochar was found to be better at minimizing the bacteria being studied. This research helped to find ways to improve the efficiency of gray-water for reuse. The study verified that the quality of graywater through filtration can be increased and showed that the degree of deficiency depends on the filter material used and the characteristics of the microorganism [10].

The potential for treated greywater to be used as a water supply is strong. This study analyzes the graywater disposal of most types of bacteria, phages, and germs by biochar, bark, activated carbon and mixture of activated carbon and bark filtration. In column experiments (height $65 \mathrm{~cm}$, diameter: $4.3 \mathrm{~cm}$ ), the reduction of pathogen and indicator species over a period of 63 days was studied to supply artificial greywater at a hydraulic loading rate and an organic loading rate. Biochar filters have been shown to be more efficient than other filters in removing Salmonella spp., and less efficient in removing bacteriophages. Bark and mixture filters were ineffectively used to remove pathogenic and indicator species. In the first half of the experimental period, strong decreases in pathogenic and indicator species were observed in activated carbon filters [11].

The shortage of safe water supplies is becoming a rising issue with a growing world population. This issue could be alleviated by reusing greywater. It is important to ensure the elimination of pathogenic species when reusing greywater for crop irrigation. The 
main objective of this research is to compare traditional sand filters in terms of eliminating bacteria, phages and viruses, and the filters with which we use alternative filter materials such as pine bark and activated charcoal filters with three organic loading rates. There was a significant decrease in the clearance of the bacterium, Escherichia, Escherichia coli, and an increase in the organic loading rate in the charcoal and sand filter. As for the filter of pine and sand bark, the efficiency of removing bacteria and viruses has increased. Therefore, this research proved that the bark is one of the good materials in graywater treatment in terms of removing pathogens [12].

The focus of this work was also on the concentration of COD for ammonia and Dye wastewater color. In the column tests, the work evaluates the elimination of COD, also ammonia and color of dye wastewater by using granular activated carbon and zeolite. This research deals with many factors such as surface loading speeds, adsorbent height and empty bed contact time are also used to analyze the efficacy of the adsorption process [13].

The main objective of this research is to verify the efficiency of removing oil and water separation by using filtering materials with the traditional sand filter, and these materials are available and inexpensive. Four materials were chosen as filter materials, which are walnut shell, ceramite, oil sand and polyethylene. Based on laboratory tests, the separation efficiency was greater for walnut shell and oil sand as oil-soluble media. A decrease in the separation efficiency of porous media will occur as the wastewater velocity increases. The separation efficiency will also grow as the porous medium thickness increases [14].

In this paper, a treat textile wastewater treatment is studied by using a biological aerated filter. Two biofilters were monitored in a laboratory for a period of seven months, where the first biofilter was a conventional filter, and the second filter contained natural zeolite with sand as a medium. During the study period, it was found that the zeolite filter with sand has a higher efficiency in removing COD as well as total suspended solids than the traditional sand filter. The processes with high hydraulic load and lower temperatures also resulted in a decrease in the overall denitrification performance, with less effect on the reduction of organic matter. Decolorization (78 percent) was effective in a bio-filter with natural zeolite due to its absorbency, regardless of the rate of increased hydraulic loading [15].

Data show interference in fluorescence measurements related to water filtration by various filter materials, including $0.7 \mathrm{~mm}$ glass microfiber filter, $0.45 \mathrm{~mm}$ polyvinyllidene fluoride (PVDF) membrane, $0.45 \mathrm{~mm}$ cellulose nitrate membrane, and $0.45 \mathrm{~mm}$ polyethersulfone (PES) syringe filters. The data also demonstrates changes in time under various storage conditions of many fluorescence indexes and Ultraviolet Radiation absorption measurements of wastewater organic matter. Specifically, spectroscopic results were collected over a 21 day test period using $0.7 \mathrm{~mm}$ filtered and unfiltered waste water samples stored at various temperatures [16].

Various wastewater attributes, primary, secondary and tertiary wastewater effluents and surface water affected by wastewater include, were used to conduct research. $0.7 \mu \mathrm{m}$ glass microfiber filter filtration, $0.45 \mu \mathrm{m}$ polyviersulfone (PES) syringe filter released fluorescence-affected water output impurities. According to the results obtained, sample filtration at $0.7 / 0.45 \mu \mathrm{m}$ immediately after col 19 lection accompanied by storage at $4^{\circ} \mathrm{C}$ was the best practice for wastewater sample preservation. However, time for storage, which ensured changes in these spectral measurements do not pass $10 \%$ of the original value, depends on the nature of the water and the chosen wavelengths [17].

Using a pilot scale, dual-media, rapid depth filtration device, the effect of loading rate on tertiary filtration of wastewater was studied. The coagulated wastewater was passed on filter columns and placed in parallel at different loading speeds to see its effect on removing particles and getting rid of turbidity, bacteria and viruses. It was found that the higher the loading rate, the lower the filter efficiency, especially in removing particles. The effect of coagulation dose was also studied, whereby any negative effect of loading rate on removal efficiency was eliminated by controlling the coagulation dose. The results of this study demonstrated that loading rates higher than those typically used for high filtration can generate acceptable liquid water quality and encourage a regulatory approach focusing on wastewater turbidity [18].

Improved septic tank effluent treatment will enhance the hydraulic role and performance of infiltration systems and wetlands under construction. In this study an unsaturated flow system was established that removes the pathogen by intermittent spraying on a sand filter that contains coarse granules as a filter material. An increase in the elimination of bacteriophages with subsequent biofilm accumulation in the filter material by the time of operation was shown by a column filtration analysis. Regardless of their hydrophilic / hydrophobic surface properties, for $1 \mathrm{~mm}$ polystyrene beads, the same increased removal was observed [19].

Sewage treatment is often very expensive and economically expensive. Therefore, in most poor countries, irrigation water used to grow vegetables in urban areas is contaminated with untreated wastewater. The continued use of this irrigation water also poses health risks to vegetable consumers and farmers. In this study, work was done to reduce health risks by delivering irrigation water to three sand filters, each one containing different filter materials, in order to get rid of bacteria, parasitic worms and other pollutants. Nylon, cotton, and mesh fabric filters were used (Fig. 2). Over 600 water samples were examined for the eggs of 
parasitic worms and refractory coliforms. It was found that the cloth filters made of cotton and net are less efficient in removing worms, while the nylon filter gave higher efficiency in removing worms and coliforms [20].

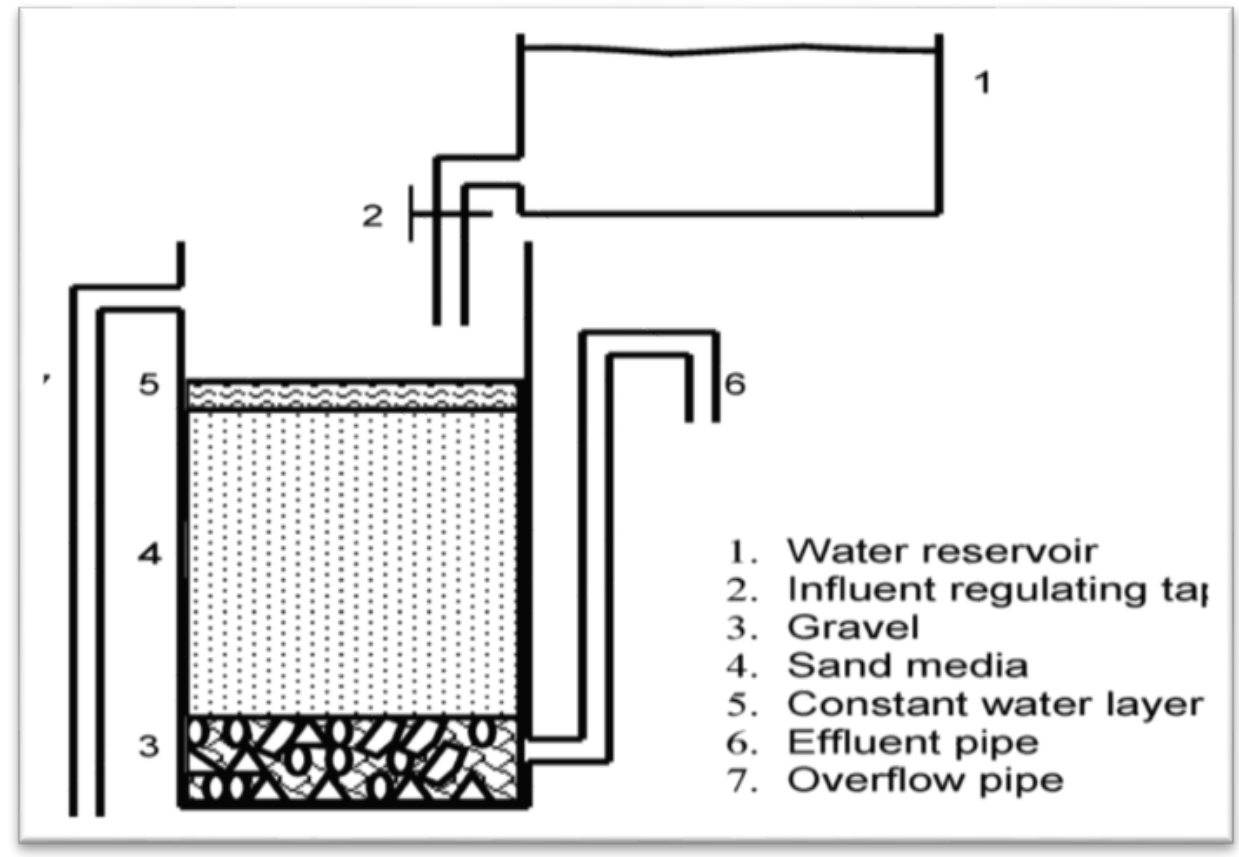

Fig. 2: Show of sand filter [20]

This study aims to experiment with anaerobic treatment of domestic wastewater effluents, which contain suspended solids, toxic materials, organic materials, nutrients and toxins, at concentrations much higher than the permissible limit. The septic tank was supplied to a conventional sand filter on one side, and on the other side by the up flow anaerobic sludge blanket (UASB). It was found that the efficiency of the UASB was much higher than that of the sand filter, the efficiency of the UASB, the removal efficiency of suspended solids, the chemical oxygen demand and the fecal coliform removal efficiency were 93 percent, 87 percent and 93 percent, respectively. In order to maintain high filtration quality, it is important to replace the top layer of sand in the filter every two to three months. The result can be useful in designing and building an efficient, lightweight and cost-effective sewage system for poor countries [21].

Due to the shortage of fresh water, the availability of treated wastewater, in theory, can be used as an alternative source for irrigation water. The purpose of this study is to use treated wastewater for irrigation of red amaranth seed. As this water was delivered with six sand filters that contain different filter materials. The first sand filter is the traditional filter that contains only sand, while the second filter contains sand and wood charcoal, the third filter contains sand, wood charcoal and rice husks, the fourth filter contains sand, wood charcoal, rice husks and sawdust, and the fifth filter contains sand and wood charcoal Rice husks, sawdust, and brick chips. The sixth filter contains sand, wood charcoal, rice husks, sawdust, brick chips and gravel. The results indicated that the fifth filter is the best type, as the efficiency of removing BOD5, COD, solid suspended matter, as well as the efficiency of removing the heavy metals, was higher than that of the rest of the filters. In addition to that, the fifth candidate had the highest seed germination (67.14\%), the ratio of healthy plants to the pot $(93.62 \%)$ was much higher than the rest of the filters [22].

This study was conducted for wastewater treatment in urban areas. Three experimental stations, each consisting of a septic pit, were used, followed by a sand filter containing desert dune sand as a filter material. The experiments were conducted in the three stations simultaneously for a period of 2.5 months, and the results were that the efficiency of $\mathrm{BOD}_{5}$, COD and SS removal is $70 \%$ higher than the regular filters to allow the permeability of sand dunes in their use in biological filtration of water, but consideration should be given to additional drainage to avoid salt problems [23.

This study was conducted on domestic wastewater treatment. Where a two-layer filtration system was established, sand and sand dunes were used in the first filter as filter materials, while the second filter contained activated carbon and sand. The efficiency of the filtration process was calculated by calculating the removal of both $\mathrm{BOD}_{5}$ and $\mathrm{COD}$, the comparison of these findings with those obtained with a sand dune bed only showed strong efficiency improvements ranging from 80-95 \% for COD and 78-94 \%) for $\mathrm{BOD}_{5}$ [24]. 


\section{CONCLUSION}

the following noticeable points are obtaining from the present paper:

1. In view of the above results, a promising alternative for large-scale pilot development is the valorisation of the sand dune tools used as a filtering aid for wastewater treatment. Indeed, this option will make it possible to reduce the use of expensive strategies that entail enormous means of management and maintenance.

2. Through the studied results, the filtration method in which we use biochar as a filtration material is ineffective in the water we use for irrigation. Cerevisiae S. has been successfully eliminated by the filter containing the biochar, but it is considered low in bacterial removal and most viruses.

3. The vertical and horizontal flow filtration system that uses biochar as the filter material is one of the best filters in wastewater treatment. This is due to the efficiency in removing more than $90 \%$ of the organic matter and more than $70 \%$ of the removal of nitrogen, in addition to the ability to eliminate most types of bacteria and viruses.

4. Municipal wastewater anaerobic filtration is a highly suitable and low-cost technology for removing COD, TOC and turbidity, especially in poor countries where wastewater treatment processes are often insufficient.

5. Anaerobic treatment (UASB) for household wastewater effluent treatment can also be considered a low-cost alternative filtration media to avoid daily sand replacement.

6. The treatment of dye waste water with GAC and zeolite adsorbents was investigated in the column phase under various experimental conditions. Basically, the parameters for assessing the reduction of pollutants are found to depend on the surface loading rate (SLR), adsorbent bed depth, the contact time of the empty bed and the type of adsorbent used.

\section{REFRENCES}

[1] L. Taoufiq, A. Laamyem, A. Boukhair, E. Essediqi, M. Monkade and A. Zrabda, "Radiological assessment of wastewater treatment processes based on the use of coal ashes as a filters," Journal of Radiation Research and Applied Sciences, vol. 11, pp. 217-224, 2018.

[2] K. Khengaoui, M. Mahammed, Y. Touil and A. Amrane, "Influence of secondary salinity wastewater on the efficiency of biological treatment of sand filter," in International Conference on Technologies and Materials for Renewable Energy, Environment and Sustainability, 2015.

[3] R. Kurniawan, N. E. Kristanti and A. C. Sukartiko, "Wastewater Treatment in Cajuput Oil Industry using Anaerobic Filtration," in International Conference on Agro-industry (ICoA): Competitive and sustainable Agroindustry for Human Welfare, 2015.

[4] Y. W. Kang, K. M. Manel and O. H. Twovinen, "Treatment of turkey processing wastewater with sand filtration," Bioresource Technology, pp. 98: 1460-1466, 2007.

[5] O. Lefebvre and R. Moletta, "Treatment of organic pollution in industrial saline waste water: A literature review," Water Research, p. 40: 3671, 2006.

[6] R. L. Valentine, T. S. Mulholland and R. C. Splinter, "Radium Removal Using Sorption to Filter Sand," American Water Works Association, pp. 170-176, 1987.

[7] L. Fernando, P. Mercado, C. Lalander, A. Joel, J. Ottoson, S. Dalahmeh and B. Vinneras, "Biochar filters as an on-farm treatment to reduce pathogens when irrigating with wastewater-polluted sources," Journal of Environmental Management, vol. 248, p. 109295, 2019.

[8] S. S. Dalahmeh, A. Assayed and Y. Stenstrom, "Combined Vertical-Horizontal Flow Biochar Filter for OnsiteWastewater Treatment—Removal of Organic Matter, Nitrogen and Pathogens," Applied Science, vol. 9, p. 5386, 2019.

[9] K. Kaetzl, M. Lubken, T. Gehring and M. Wichern, "Efficient Low-Cost Anaerobic Treatment of Wastewater Using Biochar and Woodchip Filters," water, pp. (10): 1-17, 2018.

[10] M. Sidibe, Comparative Study of Bark, Bio-Char, Activiated Charcoal Filters for Upgrading Grey - Water, Master. SLU: 
International Journal of Advances in Scientific Research and Engineering (ijasre), Vol 6 (11), November -2020

Swedish University of Agricultural Sciences, 2014.

[11] R. Molaei, Pathogen and Indicator Organisms Removal in Artificial Greywater Subject to Aerobic Treatment, Master. SLU: Swedish University of Agricultural Sciences, 2014.

[12] C. Lalander, S. Dalahmeh, H. Jonsson and B. Vinneras, "Hygienic quality of artificial greywater subjected to aerobic treatment: a comparison of three filter media at increasing organic loading rates," Environmental Technology, pp. 37-41, 2013.

[13] S. Syafalni, I. Abustan, I. Dahlan, C. Kok Wah and G. Umar, "Treatment of Dye Wastewater Using Granular Activated Carbon and Zeolite Filter," Modern Applied Science, pp. Vol. 6 (2): 37-51, 2012.

[14] D. Zhang, x. Wu and L. Zhang, "Effect of different filtration materials on oil and water separation efficiency," in 5th Global Conference on Materials Science and Engineerin, 2017.

[15] W. S. Chag, S. W. Hong and J. Park, "Effect of zeolite media for the treatment of textile wastewater in a biological aerated filter," Process Biochemistry, pp. 37: 693-698, 2002.

[16] M. Sgroi, E. Gaglino, F. Vagliasindi and P. Roccaro, "Data on the effects of filters, storage conditions, and chlorination in fluorescence and absorbance wastewater measurements," Data in brief, p. 28: 105099, 2020.

[17] M. Sgroi, E. Gahliaco, F. Vagliasindi and P. Roccaro, "Absorbance and EEM fluorescence of wastewater: Effects of filters, storage conditions, and chlorination," Chemosphere Journal, p. 10: 125292, 2019.

[18] G. J. Williams, B. Sheikh, R. B. Holden, T. J. Kouretas and k. L. Nelson, "The impact of increased loading rate on granular media, rapid depth filtration of wastewater," WATER RESEARCH JOURNAL, pp. Vol. 41(3), 4535-4545, 2007.

[19] A. Heistad, T. Scott, A. M. Skaarer, R. Seidu, J. Hanssen and T. Stenstrom, "Virus removal by unsaturated wastewater filtration: effects of biofilm accumulation and hydrophobicity," Water Science \& Technology, pp. Vol. 60 (2): 399-407, 2009.

[20] B. Keraita, P. Drechsel, F. Konradsen and R. Vreugdenhil, "Potential of simple filters to improve microbial quality of irrigation water used in urban vegetable farming in Ghana," Journal of Environmental Science and Health, pp. 43: 749755,2008 .

[21] S. P. Lohani, S. N. Khanal and R. Bakke, "A simple anaerobic and filtration combined system for domestic wastewater treatment," Water-Energy Nexus, pp. (3): 41-45 , 2020.

[22] G. C. Biswas, A. Sakar, M. H. Rashid, M. H. Shohan, M. Islam and Q. Wang, "Assessment of the irrigation feasibility of low-cost filtered municipal," International Soil and Water Conservation Research, pp. (3): 239-252, 2015.

[23] Touil, Y., Taha, S., Issaadi, R., \& Amrane, A. (2009). Pilot plant for wastewater treatment involving septic pit and biological filtration on sand of dunes of the Algerian Sahara. Desalination and Water Treatment, 10: 148-152. doi:10.5004/dwt.2009.819

[24] G. Yamina, A. Abdeltif, T. Youcef, H. Mahfoud, G. Fatiha and B. lotfi, "A Comparative Study Of The Addition effect Of Activated Carbon Obtained From Date Stones On The Biological Filtration Efficiency Using Sand Dune Bed," in TerraGreen 13 International Conference 2013 - Advancements in Renewable Energy and Clean Environment, 2013. 